\title{
Metabolismo de nutrientes em ovinos alimentados com casca de soja em substituição ao feno de coastcross ${ }^{1}$
}

\author{
Renato Shinkai Gentil ${ }^{2}$, Ivanete Susin ${ }^{3}$, Alexandre Vaz Pires ${ }^{3}$, Evandro Maia Ferreira ${ }^{2}$, \\ Clayton Quirino Mendes ${ }^{2}$, Omer Cavalcanti de Almeida ${ }^{2}$, Mário Adriano Ávila Queiroz ${ }^{2}$
}

\footnotetext{
${ }^{1}$ Apoio Conselho Nacional de Desenvolvimento Científico e Tecnológico.

2 Pós-graduação em Ciência Animal e Pastagens - USP/ESALQ - Piracicaba, SP.

${ }^{3}$ Departamento de Zootecnia - ESALQ/USP - Pesquisador CNPq.
}

RESUMO - O objetivo neste experimento foi avaliar os efeitos da substituição do feno de coastcross (Cynodon sp.) por casca de soja sobre a digestibilidade aparente dos nutrientes, os parâmetros ruminais e o metabolismo de nitrogênio. Dezesseis borregos ( $\mathrm{PV}=40,0 \pm 5 \mathrm{~kg}$ ) foram individualmente alojados em gaiolas metálicas para ensaio de metabolismo em delineamento experimental do tipo blocos completos casualizados. O experimento teve duração de 14 dias, sendo 10 dias para adaptação dos animais às rações experimentais e 4 para coleta das amostras. Os animais foram alimentados com dietas compostas de $50 \%$ de volumoso e $50 \%$ de concentrado com mesmo teor de fibra em detergente neutro (FDN). A casca de soja substituiu o feno de coastcross em 0,33, 67 ou 100\% da matéria seca. Os teores de casca de soja na dieta tiveram efeito quadrático sobre os consumos de matéria seca e FDN. Contudo, observou-se aumento da digestibilidade da MS e FDN, enquanto a concentração de ácidos graxos de cadeia curta, acetato e propionato não se alteraram e o pH ruminal e a concentração de $\mathrm{N}$-amoniacal diminuíram. A substituição parcial do feno de coastcross por casca de soja aumenta o consumo de matéria seca e diminui o $\mathrm{pH}$ ruminal sem prejudicar a digestibilidade da MS e FDN.

Palavras-chave: ácidos graxos de cadeia curta, subproduto, FDN efetiva, rúmen

\section{Nutrient metabolism in sheep fed soybean hulls replacing coastcross hay}

\begin{abstract}
The objective of this experiment was to determine the effects of replacing coastcross hay (Cynodon sp.) by soybean hulls on nutrient apparent digestibility, ruminal measures and nitrogen metabolism. Sixteen ram lambs ( $40 \pm 5 \mathrm{~kg}$ of body weight) were housed individually in metabolism crates and assigned to a randomized completely block design The experimental period consisted of 14 days; the first 10 days were used to adapt lambs to treatments and 4 other days for data collection. Animals were fed diets containing 50\% concentrate and 50\% roughage, both with the same amount of neutral detergent fiber (NDF). Soybean hulls replaced coastcross hay by $0,33,67$ or $100 \%$ in the dry matter. Dry matter (DM) intake and NDF showed quadratic effect when soybean hulls were added to the diet. However, DM and NDF digestibility increased, while shortchain fatty acids, acetate and propionate concentration did not change and ruminal $\mathrm{pH}$ and ammonia decreased. Partially replacing coastcross hay by soybean hulls increases DM intake and lowers ruminal pH without affecting DM or NDF digestibility.
\end{abstract}

Key Words: byproducts, effective NDF, rumen, short-chain fatty acids

\section{Introdução}

Em virtude da intensificação dos sistemas de produção e da melhoria do potencial genético dos animais, aumentar o consumo de energia para atender o crescente potencial produtivo é uma tendência na formulação de rações. Ao mesmo tempo, deve-se atentar aos limites mínimos de fibra na dieta para evitar desordens metabólicas, principalmente acidose ruminal, em animais alimentados com dietas contendo alta proporção de concentrado.

A densidade energética da casca de soja é superior à do feno de coastcross. Como exemplo, a casca de soja apresenta $77,0 \%$ de NDT e o feno de coastcross $53,0 \%$ de NDT (NRC, 2007). Além disso, o teor de FDN da casca de soja ( $65,2 \%$ da MS) é semelhante ao do feno de coastcross (75,0\% da MS) (Araujo et al., 2008a). Portanto, com a utilização da casca de soja em substituição a parte da fonte de forragem, é possível aumentar a densidade energética da dieta sem causar grandes reduções no fornecimento de FDN. Em sua composição, a casca de soja contém ainda $13,0 \%$ de PB; $2,6 \%$ de EE; 46,0\% de FDA (NRC, 2007); $2,9 \%$ de amido (Ipharranguerre \& Clark, 2003); 43,0\% de celulose; $18,0 \%$ de hemicelulose e $1,4 \%$ de lignina ( $\%$ da MS) (Mulligan et al., 1999). 
Alguns autores avaliaram o uso da casca de soja em substituição a fontes de forragem em dietas para ruminantes (Araujo et al., 2008b; Halachmi et al., 2004; Morais et al., 2006; Souza et al., 2009). Sabe-se que a substituição de fontes de forragem pela casca de soja em dieta para ovinos aumenta a digestibilidade da MS e da FDN (Araujo et al., 2008b; Morais et al., 2006). Com relação aos efeitos desta substituição no metabolismo ruminal, vários trabalhos conduzidos com vacas em lactação comprovam que a utilização da casca de soja mantém ou aumenta a concentração ruminal dos ácidos graxos de cadeia curta totais, aumenta a concentração de propionato (Ipharraguerre \& Clark, 2003) e não afeta a concentração de acetato e butirato (Weidner \& Grant, 1994a), resultando em decréscimo no pH ruminal (Sarwar et al., 1992; Grigsby et al., 1993). Entretanto, existem poucas informações a este respeito em ovinos.

A substituição de forragem por casca de soja reduz o tempo de ruminação por vacas em lactação (Ipharraguerre \& Clark, 2003). Contudo, o tempo de ruminação em ovinos é 9 a 16 vezes maior que em bovinos (De Boever et al., 1990) e isso sugere que, nos ovinos, a substituição do feno pela casca de soja causa alterações no padrão fermentativo da fibra no rúmen e na digestibilidade dos nutrientes diferentes das observadas em bovinos.

Assim, objetivou-se avaliar o efeito da substituição parcial ou total do feno de coastcross pela casca de soja sobre o consumo e a digestibilidade aparente dos nutrientes, o balanço de nitrogênio e os parâmetros ruminais de borregos da raça Santa Inês.

\section{Material e Métodos}

Foram utilizados 16 borregos da raça Santa Inês canulados no rúmen (peso corporal inicial de $40 \pm 5 \mathrm{~kg}$ e sete meses de idade) distribuídos em delineamento experimental de blocos completos casualizados, determinados de acordo com o peso e idade dos animais. Os animais foram alojados individualmente em gaiolas metálicas para ensaios de metabolismo, com dimensões de $1,30 \times 0,55 \mathrm{~m}$, providas de cocho, bebedouro e sistema para coleta de fezes e urina separadamente.

O período experimental teve duração de 14 dias: 10 dias para adaptação dos animais às rações e 4 dias para colheita de dados e amostras. Os animais foram pesados no início e no final do período experimental para posterior avaliação da variação do peso corporal.

As dietas experimentais foram isonitrogenadas e continham a mesma quantidade de FDN, com $50 \%$ de volumoso e $50 \%$ de concentrado (Tabela 1 ), com casca de soja em substituição a $0,33,67$ ou $100 \%$ do feno de coastcross moído.

A alimentação foi fornecida ad libitum, uma vez ao dia, permitindo-se sobras de no máximo $10 \%$ da quantidade oferecida. $\mathrm{O}$ alimento oferecido e as sobras foram pesados diariamente em balança eletrônica (LC100, Marte Balanças

Tabela 1 - Proporção dos ingredientes e composição química das rações experimentais (\% na MS)

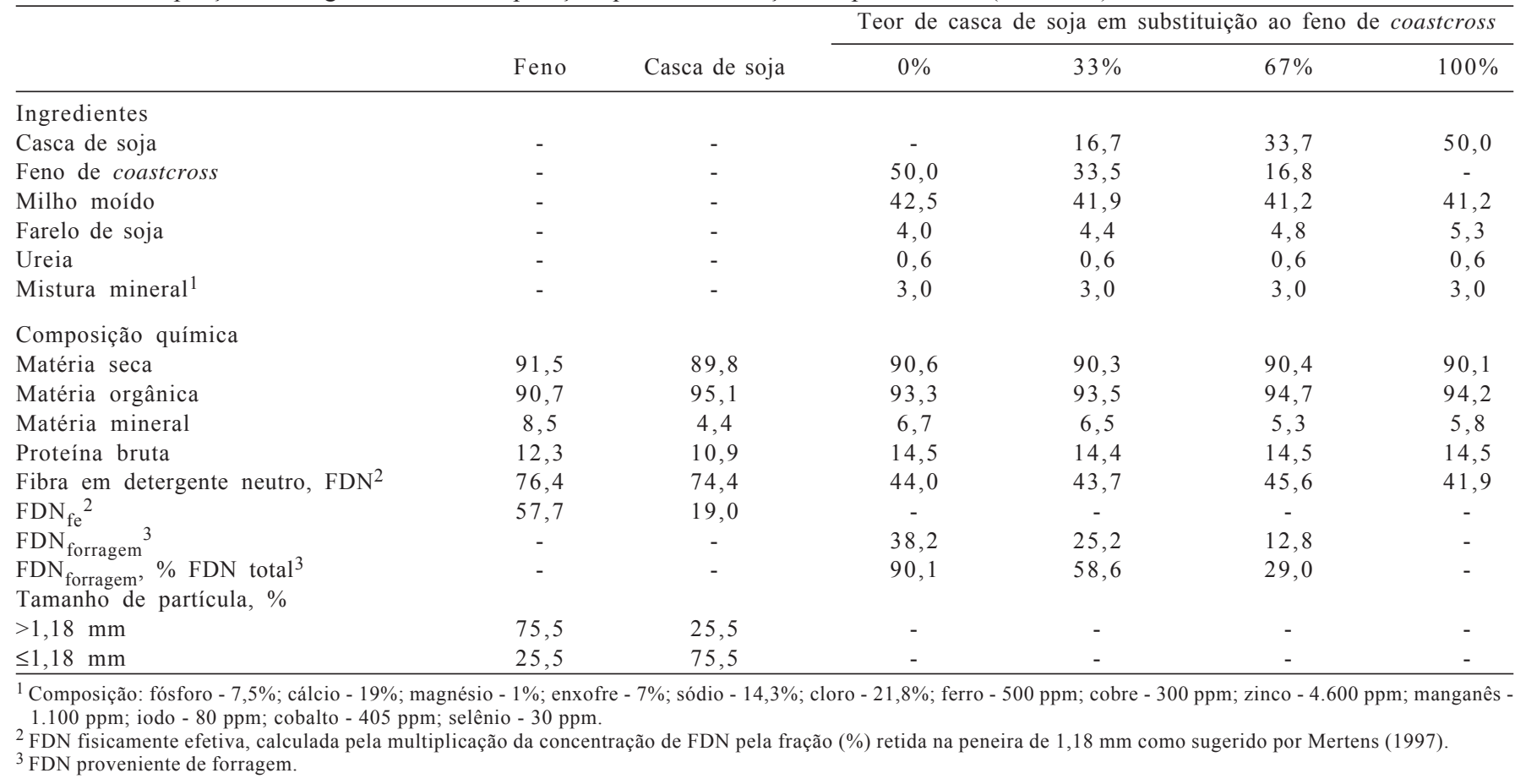


e Aparelhos de Precisão LTDA) com precisão de 20 g para determinação do consumo de MS por animal por dia. Durante os quatro dias de colheita, amostras das fezes e dos alimentos oferecidos e recusados foram colhidas e compostas por animal e conservadas a $-18^{\circ} \mathrm{C}$.

As amostras colhidas foram analisadas no Laboratório de Bromatologia do Departamento de Zootecnia da ESALQ - USP depois de moídas em moinho tipo Wiley com peneira com crivo de $1 \mathrm{~mm}$. As determinações de MS e matéria mineral (MM) foram realizadas de acordo com a AOAC (1990) e FDN segundo Van Soest et al. (1991) com a utilização de sulfito de sódio e $\alpha$-amilase. A determinação de nitrogênio total das fezes e dos alimentos foi realizada com base na combustão das amostras (Wiles et al., 1998) pelo analisador da marca LECO $^{\circledR}$, modelo FP-528, com temperatura para combustão de $835^{\circ} \mathrm{C}$. O teor de proteína bruta (PB) foi obtido por meio da multiplicação do teor de nitrogênio total por 6,25 e o de matéria orgânica pela diferença entre a matéria seca e matéria mineral.

A digestibilidade aparente dos nutrientes foi calculada da seguinte forma:

$$
\mathrm{CD}(\%)=\frac{(\mathrm{MSC} * \mathrm{NMS})-(\mathrm{MSF} * \mathrm{NMF})}{(\mathrm{MSC} * \mathrm{NMS})} * 100
$$

$\mathrm{MSC}=$ matéria seca consumida; $\mathrm{NMS}=$ porcentagem do nutriente na matéria seca consumida; $\mathrm{MSF}=$ matéria seca fecal; NMF = porcentagem do nutriente na matéria seca fecal.

Realizou-se a colheita total de urina uma vez por dia durante o período de colheita de amostras. A urina foi colhida em recipientes plásticos contendo solução de ácido clorídrico $(\mathrm{HCl} 6 \mathrm{~N})$, a fim de manter o $\mathrm{pH}$ da urina abaixo de 3. O total colhido foi quantificado e homogeneizado, sendo em seguida filtrado em gaze de algodão e uma amostra de $10 \%$ foi retirada e congelada a $-18{ }^{\circ} \mathrm{C}$. O nitrogênio da urina foi determinado em micro Kjeldahl (Campos et al., 2004).

$\mathrm{O}$ balanço de nitrogênio foi calculado pelas fórmulas abaixo apresentadas:

Nitrogênio absorvido $(g / d)=N$ consumido $-\mathrm{N}$ fecal

Nitrogênio retido $(\mathrm{g} / \mathrm{d})=\mathrm{N}$ absorvido $-\mathrm{N}$ urinário

Balanço de $\mathrm{N}(\% \mathrm{~N}$ absorvido $)=(\mathrm{N}$ retido $/ \mathrm{N}$ absorvido)*100

Balanço de $\mathrm{N}(\% \mathrm{~N}$ ingerido $)=(\mathrm{N}$ retido $/ \mathrm{N}$ ingerido $) * 100$

As amostras de conteúdo ruminal foram obtidas no último dia de colheita do período experimental, em intervalos de duas horas entre colheitas. Os horários de colheita tiveram como início o momento da alimentação, sendo a hora zero o momento antes da oferta de alimento e 2, 4, 6, 8, 10 e 12 horas após o fornecimento do alimento.
A colheita das amostras foi realizada em quatro regiões distintas da cavidade ruminal. Depois, as amostras foram filtradas em tecidos de algodão do tipo fralda e cada amostra teve, aproximadamente, $200 \mathrm{~mL}$ de fluido ruminal filtrado, utilizados na determinação imediata do $\mathrm{pH}$ de cada amostra, por meio de pHmetro (DM - 20, Digimed).

A seguir, uma alíquota de $25 \mathrm{~mL}$ do fluido, acrescentando $1,25 \mathrm{~mL}$ de solução $6 \mathrm{~N}$ de $\mathrm{HCl}$, foi conservada a $-18{ }^{\circ} \mathrm{C}$ para posterior determinação dos ácidos graxos de cadeia curta (AGCC) e $\mathrm{N}$-amoniacal. Após o descongelamento, as amostras foram centrifugadas a $12.000 \mathrm{x} \mathrm{g}$ a $4^{\circ} \mathrm{C}$ durante 20 minutos. Uma alíquota do sobrenadante foi utilizada para determinação do $\mathrm{N}$-amoniacal, seguindo o método colorimétrico proposto por Chaney \& Marbach (1962), adaptado para a leitura em leitor de microplaca (Bio-Rad, Hercules, EUA), utilizando-se filtro para absorbância de $540 \mathrm{~nm}$ (Campos et al., 2004).

A outra alíquota sobrenadante foi utilizada para determinação da concentração dos AGCC em cromatógrafo gasoso (CG), segundo Palmquist \& Conrad (1971). As amostras foram previamente preparadas e armazenadas sob refrigeração $\left(-18{ }^{\circ} \mathrm{C}\right)$ em recipientes apropriados, contendo $800 \mu \mathrm{L}$ do extrato, $200 \mu \mathrm{L}$ de ácido fórmico e $100 \mu \mathrm{L}$ de padrão interno. O equipamento utilizado foi um CG (Hewlett Packard Company ${ }^{\circledR} 5890$ serie II), equipado com braço mecânico (HP integrator 3396 serie II, Hewlett Packard Company ${ }^{\circledR}$ ).

Os dados relativos ao ensaio de digestibilidade e ao balanço de nitrogênio foram analisados pelo procedimento PROC MIXED do pacote estatístico SAS (2001). Testes para polinômios ortogonais (linear e quadrático) para todas as variáveis analisadas foram aplicados quando detectado efeito de tratamento $(\mathrm{P}<0,05)$.

O modelo estatístico utilizado para as variáveis dos coeficientes de digestibilidade aparente dos nutrientes e balanço de nitrogênio foi:

$$
\mathrm{Yijk}=\mu+\mathrm{Bi}+\mathrm{Tj}+\mathrm{Eij}
$$

em que: $\mu=$ média geral; $\mathrm{Bi}=$ efeito de bloco; $\mathrm{T} j=$ efeito de tratamento; Eij = erro aleatório associado a cada observação Yijkl.

As análises de $\mathrm{pH}, \mathrm{N}-\mathrm{NH}_{3}$ e AGCC foram realizadas por parcela subdividida no tempo (hora das medidas) pelo procedimento MIXED do pacote estatístico SAS (2001) e seguiu o seguinte modelo estatístico:

$$
\text { Yijk }=\mu+B i+T j+H j+T H i j+E i j k
$$

em que: $\mu=$ média geral; $\mathrm{Bi}=$ efeito do bloco; $\mathrm{T} j=$ efeito do tratamento; $\mathrm{Hj}=$ efeito do horário de medição; $\mathrm{THij}=$ efeito da interação entre o efeito do tratamento e o horário de medição; Eijk = erro aleatório associado a cada observação Yijkl. 


\section{Resultados e Discussão}

Houve efeito quadrático $(\mathrm{P}<0,05)$ dos teores de substituição do feno de coastcross por casca de soja sobre os consumos de matéria seca (CMS) e matéria orgânica (CMO) (Tabela 2). Com as substituições parciais do feno, observou-se aumento do consumo, contudo, no nível de $100 \%$ de substituição ao feno de coastcross, foi constatada redução da ingestão de MS. Os dados indicam dois efeitos diversos que podem ter ocasionado este resultado. No primeiro momento, com a diminuição da fibra proveniente de forragem, reduz-se o efeito de saciedade, devido ao enchimento ruminal. Araujo et al. (2008a) sugeriram que forragens aumentam o peso e o volume do rúmen, que estimulam os receptores da parede ruminal responsáveis pelo envio de sinais aos centros de saciedade do cérebro. Além disso, em razão do menor tamanho de partículas (Tabela 1), da maior gravidade específica (Bhatti \& Firkins, 1995) e da alta digestibilidade da fibra da casca de soja (Hsu et al., 1987), verifica-se elevação da taxa de passagem e degradação dos alimentos que contêm este coproduto, o que pode favorecer o aumento da ingestão de MS. De acordo com Poppi et al. (1980), partículas retidas em crivos $\geq 1,18 \mathrm{~mm}$ necessitam ser moídas em tamanho menor para que possam deixar o retículo-rúmen de ovelhas.

A redução do consumo de MS com a adição de $50 \%$ de casca de soja na ração pode ser explicada pela ausência, nesta dieta, de fibra proveniente de forragem, visto que os animais deste tratamento apresentaram $\mathrm{pH}$ ruminal igual a 5,95 (Tabela 4). Valores de $\mathrm{pH}$ menores que 6,0 podem levar à acidose subclínica, que tem como primeiro sinal clínico a redução no consumo de MS (Owens et al., 1998).

Resultados de consumo de MS de estudos com utilização de casca de soja em substituição a forragens na alimentação de ruminantes são inconsistentes. Em pesquisas com ovinos Santa Inês, autores demonstraram aumento no consumo (Araujo et al., 2008b; Morais et al., 2006; Morais et al., 2007). Por outro lado, Halachmi et al. (2004), Miron et al. (2004) e Sarwar et al. (1992) não encontraram efeito da inclusão da casca de soja. Harmison et al. (1997) observaram redução do consumo em rações contendo 23,3 e 30,6\% de casca de soja em substituição a silagens de alfafa e de milho.

Os consumos de fibra em detergente neutro (FDN) e proteína bruta $(\mathrm{PB})$ apresentaram efeito quadrático $(\mathrm{P}<0,05)$ com a adição da casca de soja nas rações. Esses resultados estão relacionados ao efeito quadrático também observado para o consumo de MS (Tabela 2), uma vez que as dietas apresentaram teores semelhantes de PB e FDN (Tabela 1).

A digestibilidade da matéria seca (DMS) e da matéria orgânica $(\mathrm{DMO})$ aumentou $(\mathrm{P}<0,05)$ à medida que foi adicionada casca de soja à dieta e este efeito possivelmente foi devido à digestibilidade da FDN, que apresentou resposta linear crescente $(\mathrm{P}<0,05)$ à substituição do feno pela casca de soja.

A composição da fibra, o tamanho da partícula e o pH ruminal são fatores que podem influenciar a digestibilidade da fração fibrosa. Orskov (1982) propôs que a degradação da fibra reduz quando o $\mathrm{pH}$ ruminal está abaixo de 6,2. Neste trabalho, o pH ruminal (Tabela 4) alcançou valores inferiores ao mencionado anteriormente, no entanto, sem prejudicar

Tabela 2 - Consumo e digestibilidade aparente no trato digestório total de nutrientes de rações contendo casca de soja em substituição parcial ou total ao feno

\begin{tabular}{|c|c|c|c|c|c|c|c|}
\hline \multirow[t]{2}{*}{ Item } & \multicolumn{4}{|c|}{ Teor de casa de soja em substituição do feno de coastcross } & \multirow[t]{2}{*}{ EPM } & \multicolumn{2}{|c|}{ Efeito $^{1}$} \\
\hline & $0 \%$ & $33 \%$ & $67 \%$ & $100 \%$ & & Linear & Quadrático \\
\hline \multicolumn{8}{|c|}{ Matéria seca } \\
\hline Consumo, kg/dia & 1,05 & 1,47 & 1,51 & 0,89 & 0,09 & 0,30 & $<0,01$ \\
\hline Consumo de MS digestível, $\mathrm{kg} /$ dia & 0,70 & 0,99 & 1,12 & 0,68 & 0,06 & 0,80 & $<0,01$ \\
\hline Coeficiente de digestibilidade, \% & 67,00 & 67,59 & 74,44 & 77,95 & 1,58 & $<0,01$ & 0,40 \\
\hline \multicolumn{8}{|c|}{ Matéria orgânica } \\
\hline Consumo, kg/dia & 1,00 & 1,38 & 1,43 & 0,85 & 0,09 & 0,32 & $<0,01$ \\
\hline Consumo de MO digestível, $\mathrm{kg} /$ dia & 0,68 & 0,94 & 1,08 & 0,67 & 0,06 & 0,69 & $<0,01$ \\
\hline Coeficiente de digestibilidade, $\%$ & 68,42 & 68,67 & 75,75 & 80,22 & 1,66 & $<0,01$ & 0,20 \\
\hline \multicolumn{8}{|c|}{ Fibra em detergente neutro } \\
\hline Consumo, kg/dia & 0,45 & 0,60 & 0,68 & 0,35 & 0,04 & 0,19 & $<0,01$ \\
\hline Consumo de FDN digestível, kg/dia & 0,25 & 0,35 & 0,47 & 0,24 & 0,03 & 0,45 & $<0,01$ \\
\hline Coeficiente de digestibilidade, $\%$ & 54,42 & 58,47 & 69,21 & 72,38 & 2,83 & $<0,01$ & 0,92 \\
\hline \multicolumn{8}{|c|}{ Proteína bruta } \\
\hline Consumo, kg/dia & 0,16 & 0,21 & 0,22 & 0,13 & 0,01 & 0,32 & $<0,01$ \\
\hline Consumo de PB digestível, $\mathrm{kg} /$ dia & 0,11 & 0,13 & 0,15 & 0,09 & $<0,01$ & 0,31 & $<0,01$ \\
\hline Coeficiente de digestibilidade, \% & 69,27 & 64,55 & 67,62 & 66,35 & 0,83 & 0,39 & 0,27 \\
\hline
\end{tabular}

EPM = erro-padrão da média.

${ }^{1}$ Efeito: valor de $\mathrm{P}$ para o teste de polinômio ortogonal, resposta cúbica não-significativa $(\mathrm{P}>0,05)$. 
a digestibilidade da FDN. Dessa forma, sugere-se que, devido à natureza da fibra da casca de soja, com baixa concentração de lignina, e ao reduzido tamanho de partícula, ocorram menor lag time na colonização pelos microrganismos (Grigsby et al., 1992) e extensiva digestão da fibra. Além disso, Sarwar et al. (1991) reportaram que, em situações em que o $\mathrm{pH}$ prejudica a digestibilidade da fibra no rúmen, pode haver digestão compensatória no intestino grosso.

Morais et al. (2006), Silva et al. (2002) e Souza et al. (2009) verificaram aumento nos coeficientes de digestibilidade dos nutrientes (MS, MO e FDN) com a inclusão da casca de soja em substituição ao feno de coastcross. Da mesma forma, a casca de soja, quando substituiu bagaço de canade-açúcar in natura, feno de alfafa emurchecido e/ou silagem de milho, ocasionou elevação da digestibilidade da FDN e MO (Halachmi et al., 2004; Mendes et al., 2010; Sarwar et al., 1991; Weidner \& Grant, 1994b). Por outro lado, Araujo et al. (2008b) verificaram que, ao adicionar casca de soja retirando-se totalmente o feno de coastcross da dieta, houve redução na digestibilidade da FDN.

Neste trabalho, a digestibilidade da proteína bruta (DPB) não apresentou diferença $(\mathrm{P}<0,05)$ entre as dietas. De acordo com a literatura, as frações proteicas de rápida e intermediária degradação (A, B1 e B2) correspondem a 75\% e $67,01 \%$ da proteína bruta da casca de soja (Hashimoto et al., 2007) e do feno de tifton 85 (Cynodon ssp.) (Ribeiro et al., 2001), respectivamente. Branco et al. (2010) encontraram efeito similar quando avaliaram os efeitos do teor de fibra proveniente de forragens na alimentação de cabras leiteiras. Souza et al. (2009) também não constataram desigualdade para esta variável ao incluírem casca de soja em rações para cabritos. No entanto, Araujo et al. (2008b) e Grigsby et al. (1992) verificaram que o aumento da casca de soja na dieta acarretou diminuição da digestibilidade da PB.

A avaliação do balanço de nitrogênio é uma ferramenta importante para balanceamento de dietas, visto que permite verificar excesso ou déficit de nitrogênio na ração. A quantidade de nitrogênio ingerido apresentou resposta quadrática $(\mathrm{P}<0,05)$ ao aumento do teor de casca de soja na ração (Tabela 3), que é reflexo da concentração similar de nitrogênio entre as dietas experimentais e do efeito quadrático observado no consumo de MS. O nitrogênio fecal excretado diariamente é influenciado diretamente pelo consumo de nitrogênio, que possivelmente propiciou, neste experimento, o efeito quadrático $(\mathrm{P}<0,05)$ para a quantidade de nitrogênio fecal (g/dia). Araujo et al. (2008b) observaram aumento de nitrogênio ingerido e fecal com a inclusão da casca de soja em substituição ao feno de coastcross. No entanto, Souza et al. (2009) não encontraram efeito da substituição do feno de coastcross por casca de soja em dietas à base de palma forrageira na quantidade de nitrogênio ingerido e fecal.

Os teores de casca de soja tiveram efeito quadrático $(\mathrm{P}<0,05)$ sobre a quantidade de nitrogênio absorvido $(\mathrm{g} / \mathrm{dia})$, que aumentou até o nível de $33,7 \%$ de inclusão de casca de soja, entretanto, quando a casca de soja foi usada em substituição total ao feno das rações, o valor de nitrogênio absorvido reduziu. Esse resultado pode ser explicado pelo consumo de PB digestível (Tabela 2), que, semelhantemente, sofreu efeito quadrático.

A excreção de nitrogênio pela urina sofreu efeito quadrático $(\mathrm{P}<0,05)$, no entanto, a maior perda, diferentemente do observado para o nitrogênio ingerido e fecal, foi observada na ausência de casca de soja, provavelmente em virtude da maior concentração de $\mathrm{N}$ amoniacal no rúmen (Tabela 4). Henning et al. (1993) também reportaram que a alta concentração e a ineficiência na utilização do nitrogênio amoniacal do rúmen podem refletir em aumento da excreção de nitrogênio pela urina. Além disso, ao melhorar a utilização de amônia no rúmen, transfere-se a excreção de nitrogênio da urina para as fezes (Hristov et al., 2005).

Ao calcular a quantidade de $\mathrm{N}$ retido ( $\mathrm{N}$ absorvido $-\mathrm{N}$ urinário), verificou-se que todas as dietas experimentais proporcionaram valores positivos, comprovando efeito quadrático $(\mathrm{P}<0,05)$ da inclusão da casca de soja nas rações.

Tabela 3 - Balanço de nitrogênio em cordeiros Santa Inês alimentados com rações contendo casca de soja em substituição parcial ou total ao feno

\begin{tabular}{|c|c|c|c|c|c|c|c|}
\hline \multirow[t]{2}{*}{ Item } & \multicolumn{4}{|c|}{ Teor de casa de soja em substituição do feno de coastcross } & \multirow[t]{2}{*}{ EPM } & \multicolumn{2}{|c|}{ Efeito $(\mathrm{P}>\mathrm{F})^{1}$} \\
\hline & $0 \%$ & $33 \%$ & $67 \%$ & $100 \%$ & & Linear & Quadrático \\
\hline $\mathrm{N}$ ingerido, $\mathrm{g} / \mathrm{dia}$ & 24,56 & 33,53 & 34,81 & 21,12 & 2,03 & 0,32 & $<0,01$ \\
\hline $\mathrm{N}$ absorvido, g/dia & 16,95 & 21,67 & 23,55 & 14,00 & 1,33 & 0,34 & $<0,01$ \\
\hline $\mathrm{N}$ urinário, g/dia & 7,64 & 3,84 & 4,30 & 3,95 & 0,57 & 0,34 & $<0,01$ \\
\hline $\mathrm{N}$ retido, $\mathrm{g} / \mathrm{dia}$ & 9,31 & 17,82 & 19,25 & 10,05 & 1,42 & 0,63 & $<0,01$ \\
\hline
\end{tabular}

$\mathrm{EPM}=$ erro-padrão da média

${ }^{1}$ Efeito: valor de $\mathrm{P}$ para o teste de polinômio ortogonal, resposta cúbica não-significativa $(\mathrm{P}>0,05)$. 
Tabela 4 - Parâmetros ruminais de cordeiros Santa Inês alimentados com rações contendo casca de soja em substituição parcial ou total ao feno

\begin{tabular}{|c|c|c|c|c|c|c|c|c|c|}
\hline \multirow[t]{2}{*}{ Item $^{1}$} & \multicolumn{4}{|c|}{ Teor de casca de soja em substituição ao feno de coastcross } & \multirow[t]{2}{*}{ EPM } & \multicolumn{2}{|c|}{ Efeito $^{1}$} & \multirow[t]{2}{*}{$\mathrm{H}$} & \multirow[t]{2}{*}{$\mathrm{T}^{*} \mathrm{H}$} \\
\hline & $0 \%$ & $33 \%$ & $67 \%$ & $100 \%$ & & Linear & Quadrático & & \\
\hline \multicolumn{10}{|l|}{ Parâmetro ruminal } \\
\hline Acetato, $\mathrm{mM}$ & 62,6 & 70,7 & 62,6 & 60,8 & 1,06 & 0,51 & 0,31 & 0,65 & 0,98 \\
\hline Propionato, mM & 7,8 & 9,4 & 11,4 & 10,8 & 0,56 & 0,37 & 0,71 & 0,47 & 0,99 \\
\hline Butirato, mM & 5,8 & 7,2 & 6,8 & 6,4 & 0,14 & 0,44 & 0,08 & 0,10 & 0,85 \\
\hline AGCC total, $\mathrm{mM}$ & 88,8 & 97,9 & 89,7 & 86,8 & 1,25 & 0,50 & 0,23 & 0,98 & 0,91 \\
\hline Acetato:propionato ${ }^{2}$ & 8,7 & 8,0 & 7,0 & 8,8 & 0,33 & 0,90 & 0,40 & 0,14 & 0,13 \\
\hline $\mathrm{pH}$ ruminal & 6,3 & 6,3 & 6,1 & 6,0 & 0,03 & 0,05 & 0,63 & $<0,01$ & 0,19 \\
\hline $\mathrm{N}-\mathrm{NH}_{3}, \mathrm{mg} / \mathrm{dL}$ & 17,5 & 17,1 & 13,7 & 15,0 & 0,54 & 0,02 & 0,41 & $<0,01$ & 0,22 \\
\hline
\end{tabular}

Em trabalhos semelhantes à este estudo, em que o feno de coastcross foi substituído pela casca de soja, foi constatado aumento na quantidade de nitrogênio retido (g/dia) (Araujo et al., 2008b; Souza et al., 2009).

A eficiência de utilização de nitrogênio é representada pelos valores de $\mathrm{N}$ retido/ $\mathrm{N}$ ingerido (\%) e $\mathrm{N}$ retido/ $\mathrm{N}$ absorvido (\%). Em ambas as variáveis, verificou-se efeito quadrático $(\mathrm{P}<0,05)$ da elevação do teor de casca de soja nas rações. Foi observado aumento da $\%$ de $\mathrm{N}$ retido/ $\mathrm{N}$ ingerido e $\mathrm{N}$ retido/N absorvido até a inclusão de $33,7 \%$ de casca de soja, contudo, com a substituição máxima de feno de coastcross pela casca de soja, a eficiência de utilização do nitrogênio reduziu. Da mesma forma, Araujo et al. (2008b) verificaram efeito quadrático sobre essas variáveis, cujos maiores valores foram obtidos com as substituições intermediárias de feno pela casca de soja.

Modificações nas concentrações dos principais AGCC produzidos pelos microrganismos ruminais dependem das características dos componentes nutricionais das dietas. Assim, embora a inclusão da casca de soja em substituição ao feno de coastcross tenha propiciado aumento no coeficiente de digestilidade da FDN das rações (Tabela 2), esse fato não alterou $(\mathrm{P}>0,05)$ a concentração de acetato $\mathrm{e}$ butirato no rúmen entre os tratamentos (Tabela 4). Esses dados estão de acordo com os observados por Souza et al. (2009) em pesquisa na qual avaliaram a substituição do feno de coastcross pela casca de soja na alimentação de caprinos jovens. Da mesma forma, Weidner \& Grant (1994a,b) adicionaram casca de soja em substituição à silagem de milho e ao feno de alfafa emurchecido e não notaram diferenças na concentração destes AGCC. No entanto, na literatura também há relatos de que a utilização da casca de soja em substituição a forragens pode levar a aumento (Grigsby et al., 1992) ou redução (Sarwar et al., 1991, 1992) da proporção de acetato e butirato no rúmen.
A concentração de propionato no rúmen não diferiu $(\mathrm{P}>0,05)$ entre os teores de casca de soja utilizados e isso ocasionou ausência de efeito $(\mathrm{P}>0,05)$ na relação acetato:propionato (A:P), uma vez que a casca de soja e o feno contêm quantidades semelhantes de FDN, resultando em teores próximos de fibra entre as dietas (Tabela 1), não influenciando, desse modo, na fermentação ruminal e nas concentrações dos ácidos graxos de cadeia curta (Figura 1). Esses resultados assemelham-se aos encontrados por Sarwar et al. (1991) e Souza et al. (2009). Por outro lado, Weidner \& Grant (1994a, b) e Sarwar et al. (1992) observaram aumento na proporção de propionato e redução da relação acetato:propionato em dietas contendo casca de soja.

Em revisão de literatura, a concentração total de ácidos graxos de cadeia curta tem se mantido ou aumentado com a inclusão da casca de soja em dietas para vacas em lactação (Ipharraguerre \& Clark, 2003). Da mesma forma, neste trabalho, não se verificou efeito $(\mathrm{P}>0,05)$ da utilização desse subproduto em substituição ao feno de coastcross, que é justificado pela semelhança entre os tratamentos dos dois principais ácidos graxos de cadeia curta (acetato e propionato) produzidos no rúmen. Em outros trabalhos para avaliação do efeito da utilização da casca de soja em substituição a forragens sobre este parâmetro ruminal, é possível observar variações nos resultados. Weidner \& Grant (1994b) constataram valores semelhantes no total de ácidos graxos de cadeia curta total, entretanto a inclusão da casca de soja, segundo Grigsby et al. (1992), Souza et al. (2009) e Weidner \& Grant (1994a), aumenta a concentração dos ácidos no rúmen. Sarwar et al. (1992) relataram que a substituição do feno de alfafa e da silagem de milho por casca de soja reduz a concentração total de ácidos graxos de cadeia curta após nove horas do fornecimento das rações.

As concentrações de acetato, propionato, butirato e ácidos graxos de cadeia curta total e a relação 
acetato:propionato não sofreram efeito $(\mathrm{P}>0,05)$ de tempo nem interação entre tratamento e tempo $(\mathrm{P}>0,05)$.

$\mathrm{O}$ pH ruminal diminuiu $(\mathrm{P}<0,05)$ com a inclusão da casca de soja em substituição ao feno de coastcross na ração. Este fato deve-se à redução da proporção de forragem, do tamanho de partículas e da efetividade física das rações contendo casca de soja. De acordo com Ipharraguerre \& Clark (2003), a amplitude do declínio do pH ruminal está ligada à quantidade e ao tamanho de partículas de forragem da dieta. Weidner \& Grant (1994a) reportaram que a quantidade de FDN na casca de soja é similar à das forragens, porém de menor efetividade em estimular a ruminação e salivação e, consequentemente, em manter o pH ruminal a valores maiores. Além disso, outros autores que avaliaram a casca de soja como substituto ao feno de coastcross verificaram alterações no comportamento ingestivo dos animais, com redução do tempo de ruminação e mastigação (Araujo et al., 2008a; Morais et al., 2006; Souza et al., 2009).

Grigsby et al. (1992) substituíram feno de bromegrass pela casca de soja em teores de até $60 \%$ da dieta e observaram efeito linear decrescente do $\mathrm{pH}$ ruminal. Da mesma forma, Souza et al. (2009) verificaram redução do pH com a adição de casca de soja em rações na alimentação de caprinos. Harmison et al. (1997) constataram que a casca de soja, ao substituir silagens de alfafa e de milho, provocou diminuição do pH fecal de vacas em lactação.

Adicionalmente, o $\mathrm{pH}$ ruminal foi influenciado $(\mathrm{P}<0,05)$ pelo tempo após a alimentação e não houve interação $(\mathrm{P}>0,05)$ entre tratamento e tempo. Os dados indicam que o pH ruminal nos teores de 0,33 e $67 \%$ de substituição do feno de coastcross pela casca de soja foi reduzindo ao longo das 12 horas após o fornecimento das rações experimentais (Figura 2). No entanto, ao retirar completamente a fibra

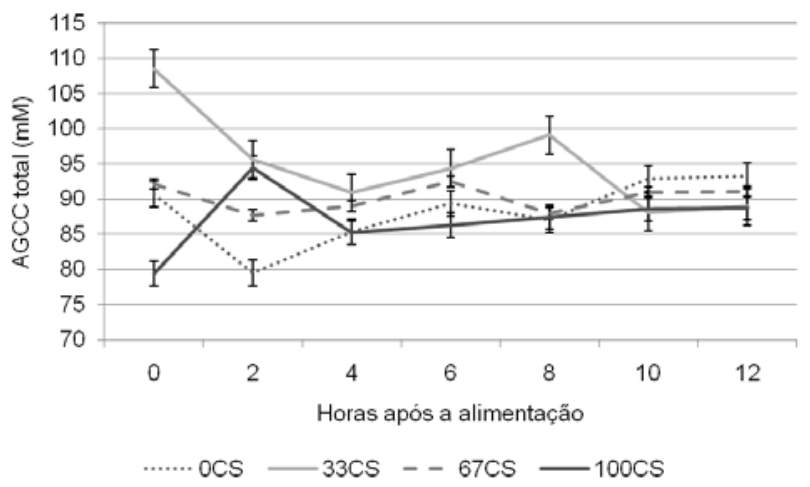

Figura 1 - Concentração molar total dos ácidos graxos de cadeia curta (AGCC) no fluido ruminal de cordeiros Santa Inês alimentados com rações contendo casca de soja em substituição parcial ao feno de coastcross. proveniente de forragens da dieta, o $\mathrm{pH}$ ruminal permaneceu sempre $\leq 6,0$, com pouca variação durante o período de colheita do conteúdo ruminal.

A concentração de $\mathrm{N}$-amoniacal no rúmen reduziu $(\mathrm{P}<0,05)$ à medida que a casca de soja foi incluída nas rações (Figura 3). Todos os valores estão acima dos 3,3 mg/dL sugeridos por Hoover (1986) como concentração mínima adequada para o desenvolvimento dos microrganismos ruminais. No entanto, o resultado encontrado pode ser atribuído à diferença de sincronização na liberação e utilização de energia e proteína entre os tratamentos. Assim, é possível que a casca de soja, por ser mais rapidamente digerida que o feno de coastcross, possibilite melhor sincronismo entre os nutrientes. Hristov et al. (2005) reportaram que o fornecimento de carboidratos rapidamente fermentescíveis pode diminuir a concentração de amônia no rúmen, em razão da melhor utilização da amônia na síntese microbiana ou da incorporação em aminoácidos pré-formados.

A concordância ou não dos resultados entre trabalhos depende dos tipos de forragem que foram substituídas pela casca de soja. Com a substituição da forragem de gramíneas, reduz a concentração de $\mathrm{N}$-amoniacal no rúmen (Grigsby et al., 1992; Souza et al., 2009). Contudo, quando incluída no lugar de feno de alfafa e silagem de milho, provoca aumento de N-amoniacal (Sarwar et al., 1991).

A concentração de $\mathrm{N}$-amoniacal no rúmen sofreu efeito de tempo $(\mathrm{P}<0,05)$, mas não houve interação entre tratamento e tempo $(\mathrm{P}>0,05)$. Em todos os tratamentos, o pico de concentração $\mathrm{N}$-amoniacal foi observado após duas horas do fornecimento das rações. Os dados estão de acordo ao verificados por Gribsgy et al. (1992), que substituíram feno de bromegrass pela casca de soja em rações fornecidas a novilhas.

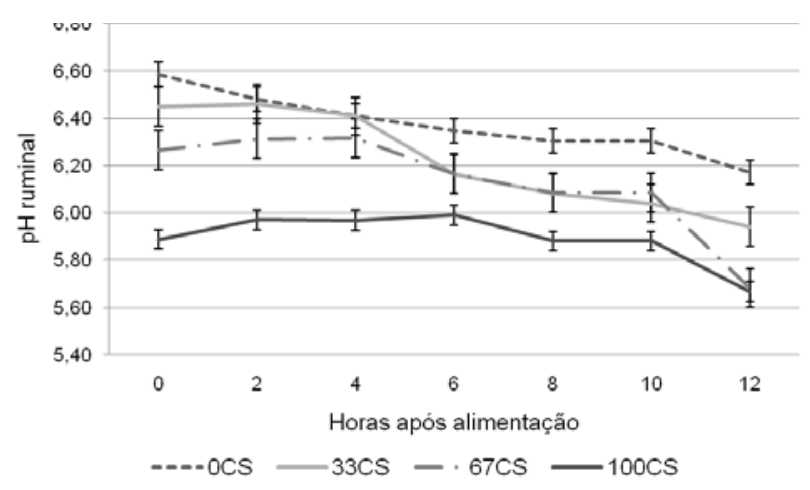

Figura 2 - pH do fluido ruminal de cordeiros Santa Inês alimentados com rações contendo casca de soja em substituição ao feno de coastcross. 


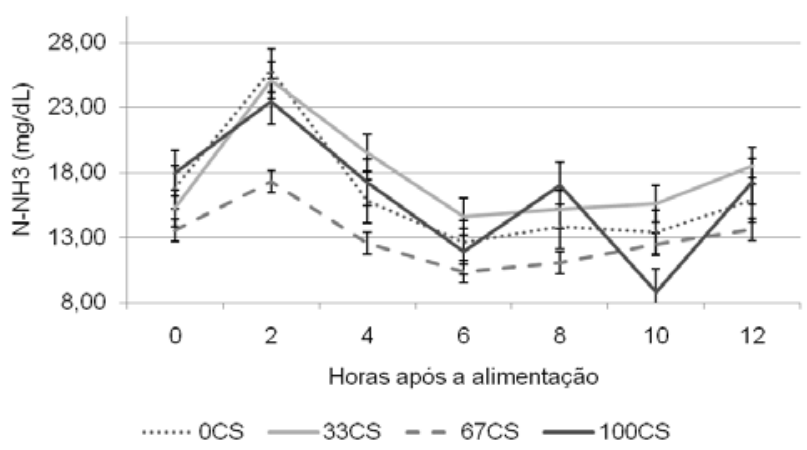

Figura 3 - Concentração de N-amoniacal no fluido ruminal de cordeiros Santa Inês alimentados com rações contendo casca de soja em substituição ao feno de coastcross.

\section{Conclusões}

O feno de coastcross pode ser parcialmente substituído por casca de soja em teores de até 33,7\% da matéria seca, visto que essa substituição aumenta o consumo de matéria seca e a retenção de nitrogênio (g/dia) sem prejudicar a digestibilidade da matéria seca, matéria orgânica e fibra em detergente neutro e a concentração de ácidos graxos de cadeia curta no rúmen.

\section{Agradecimentos}

À Fundação de Amparo à Pesquisa do Estado de São Paulo, pela bolsa concedida ao primeiro autor.

\section{Referências}

ARAUJO, R.C.; PIRES, A.V.; SUSIN, I. et al. Milk yield, milk composition, eating behavior, and lamb performance of ewes fed diets containing soybean hulls replacing coastcross (Cynodon species) hay. Journal of Animal Science, v.86, n.12, p.3511-3521, 2008a.

ARAUJO, R.C.; PIRES, A.V.; SUSIN, I. et al. Apparent digestibility of diets with combinations of soybean hulls and coastcross (Cynodon sp.) hay offered to ram lambs. Scientia Agricola, v.65, n.6, p.581-588, 2008b.

ASSOCIATION OF OFFICIAL ANALYTICAL CHEMISTS - AOAC. Official methods of analysis. 15.ed. Arlington, 1990. v.1, $1117 \mathrm{p}$.

BHATTI, S.A.; FIRKINS, J.L. Kinetics of hydration and functional specific gravity of fibrous feed by-products. Journal of Animal Science, v.73, n.5, p.1449-1458, 1995.

BRANCO, R.H.; RODRIGUES, M.T.; RODRIGUES, C.A.F. et al. Efeito dos níveis de fibra em detergente neutro oriunda da forragem sobre a eficiência microbiana e os parâmetros digestivos em cabras leiteiras. Revista Brasileira de Zootecnia, v.39, n.2, p.372-381, 2010 .

CAMPOS, F.P.; NUSSIO, C.M.B.; NUSSIO, L.G. Métodos de análises de alimentos. Piracicaba: FEALQ, 2004. 135p.

CHANEY, A.L.; MARBACH, E.P. Modified reagents for determination of urea and ammonia. Clinical Chemistry, v. 8, p.130-137, 1962 .
De BOEVER, J.L.; ANDRIES, J.I.; De BRABANDER, D.L. et al. Chewing activity of ruminants as a measure of physical structure-A review of factors affecting it. Animal Feed Science and Technology, v.27, p.281-291, 1990.

GRIGSBY. K.N.; KERLEY, M.S.; PATERSON, J.A. et al. Site and extent of nutrient digestion by steers fed a low-quality bromegrass hay diet with incremental levels of soybean hull substitution. Journal of Animal Science, v.70, n.6, p.1941-1949, 1992.

GRIGSBY, K.N.; KERLEY, M.S.; PATERSON, J.A. et al. Combinations of starch and digestible fiber in supplements for steers consuming a low-quality bromegrass hay diet. Journal of Animal Science, v.71, p.1057-1064, 1993.

HALACHMI, I.; MALTZ, E.; LIVSHIN, N. et al. Effects of replacing roughage with soy hulls on feeding behavior and milk production of dairy cows under hot weather conditions. Journal of Dairy Science, v. 87, n.7, p.2230-2238. 2004.

HARMISON, B.; EASTRIDGE, M. L.; FIRKINS, J. L. Effect of percentage of dietary forage neutral detergent fiber and source of starch on performance of lactating Jersey cows. Journal of Dairy Science, v.80, n.5, p.905-911, 1997.

HASHIMOTO, J.H.; ALCALDE, C.R.; ZAMBOM, M.A. et al. Desempenho e digestibilidade aparente em cabritos Boer $\mathrm{x}$ Saanen em confinamento recebendo rações com casca do grão de soja em substituição ao milho. Revista Brasileira de Zootecnia, v.36, n.1, p.174-182, 2007.

HENNING, P.H.; STEYN, D.G.; MEISSNER, H.H. Effect of synchronization of energy and nitrogen supply on ruminal characteristics and microbial growth. Journal of Animal Science, v.71, n.9, p.2516-2528, 1993.

HOOVER, W.H. Chemical factors involved in ruminal fiber digestion. Journal of Dairy Science, v.69, n.10, p.2755-2766, 1986.

HRISTOV, A.N.; ROPP, J.K.; GRANDEEN, K.L. et al. Effect of carbohydrate source on ammonia utilization in lactating dairy cows. Journal of Animal Science, v.83, n.2, p.408-421, 2005.

HSU, J.T.; FAULKNER, D.B.; GARLEB, K.A. et al. Evaluation of corn fiber, cottonseed hulls, oat hulls and soybean hulls as roughage sources for ruminants. Journal of Animal Science, v.65, n.1, p.244-255, 1987.

IPHARRAGUERRE, I.R.; CLARK, J.H. Soyhulls as an alternative feed for lactating dairy cows: A review. Journal of Dairy Science, v.86, n.4, p.1052-2073, 2003.

MENDES, C.Q.; TURINO, V.F.; SUSIN, I. et al. Comportamento ingestivo de cordeiros e digestibilidade dos nutrientes de dietas contendo alta proporção de concentrado e diferentes fontes de fibra em detergente neutro. Revista Brasileira de Zootecnia, v.39, n.3, p.594-600, 2010.

MERTENS, D.R. Creating a system for meeting the fiber requirements of dairy cows. Journal of Dairy Science, v. 80 , n.7, p.1463-1481, 1997.

MORAIS, J.B.; SUSIN, I.; PIRES, A.V. et al. Comportamento ingestivo de ovinos e digestibilidade aparente dos nutrientes de dietas contendo casca de soja. Pesquisa Agropecuária Brasileira, v.41, n.7, p.1157-1164, 2006.

MORAIS, J.B.; SUSIN, I.; PIRES, A.V. et al. Substituição do feno de "Coastcross" (Cynodon sp.) por casca de soja na alimentação de borregas confinadas. Ciência Rural, v.37, n.4, p.1073-2078, 2007.

MIRON, J.; YOSEF, E.; NIKBACHAT, M. et al. Feeding behavior and performance of dairy cows fed pelleted nonroughage fiber byproducts. Journal of Dairy Science, v.87, n.5, p.1372-1379, 2004.

MULLIGAN, F.P.; O’MARA, F.P.; CAFFREY, P.J. et al. The effect of feeding level on the retention time and degradability of soya hulls. In: O'KILEY, P.; STOREY, T.; COLLINS, J.F. (Eds.). Proceedings Agricultural Research Forum. Dublin: Faculty of Agriculture, 1999. p.135-136.

NAKAMURA, T.; OWEN, F.G. High amounts of soyhulls for pelleted concentrate diets. Journal of Dairy Science, v.72, n.4, p.988-994, 1989. 
NATIONAL RESEARCH COUNCIL - NRC. Nutrient requirements of small ruminants. Washington: National Academic Press, 2007. 292p

ØRSKOV, E.R. Protein nutrition in ruminants. London: Academic Press, 1982. 175p.

OWENS, F.N.; SECRIST, D.S.; HILL, W.J. et al. Acidosis in cattle: a review. Journal of Animal Science, v.76, n.1, p.275-286, 1998.

PALMQUIST, D.; CONRAD, H. Origin of plasma fatty acids in lactating cows fed high fat diets. Journal of Dairy Science, v. 54 , n.7, p.1025-1033, 1971.

POPPI, D.P.; NORTON, B.W.; MINSON, D.J. et al. The validity of the critical size theory for particles leaving the rumen. Journal of Agricultural Science, v.94, n.2, p.275-280, 1980.

RIBEIRO, K.G.; PEREIRA, O.G.; VALADARES, S.C. et al. Caracterização das frações que constituem as proteínas e os carboidratos e respectivas taxas de digestão do feno de CapimTifton 85 de diferentes idades de rebrota. Revista Brasileira de Zootecnia, v.30, n.2, p.589-595, 2001.

SARWAR, M.; FIRKINS, J.L.; EASTRIDGE, M.L. Effect of replacing neutral detergent fiber of forage with soyhulls and corn gluten feed for dairy heifers. Journal of Dairy Science, v.74, n.6, p.1006-1017, 1991.

SARWAR, M.; FIRKINS, J.L.; EASTRIDGE, M.L. Effects of varying forage or concentrate carbohydrates on nutrient digestibilities and milk production by dairy cows. Journal of Dairy Science, v.75, n. 6, p.1533-1542, 1992.
SILVA, L.D.F.; EZEQUIEL, J.M.B.; AZEVEDO, P.S. et al. Digestão total e parcial de alguns componentes de dietas contendo diferentes níveis de casca de soja e fontes de nitrogênio em bovinos. Revista Brasileira de Zootecnia, v.31, n.3, p.1258-1268, 2002.

SOUZA, E.J.; GUIM, A.; BATISTA, A.M.V. et al. Effects of soybean hulls inclusion on intake, total tract nutrient utilization and ruminal fermentation of goats fed spineless cactus (Opuntia ficus-indica Mill) based diets. Small Ruminant Research, v. 85, n.1, p.63-69, 2009.

STATISTICAL ANALYSES SYSTEM - SAS systems for windows: version 8.2. Cary: SAS INSTITUTE, 2001. 332p.

VAN SOEST, P.J.; ROBERTSON, J.B.; LEWIS, B.A. Methods for dietary fiber, neutral detergent fiber and non-starch polysaccharides in relation to animal nutrition. Journal of Dairy Science, v.74, n.10, p.3583-3597, 1991

WEIDNER, S.J.; GRANT, R.J. Altered ruminal mat consistency by high percentages of soybean hulls fed to lactating dairy cows. Journal of Dairy Science, v.77, n.2, p.522-532, 1994a.

WEIDNER, S.J.; GRANT, R.J. Soyhulls as a replacement for forage fiber in diets for lactating dairy cows. Journal of Dairy Science, v.77, n.2, p.513-521, 1994b.

WILES, P.G.; GRAY, I.K.; KISSLING, R.C. Routine analysis of proteins by Kjeldahl and Dumas methods: review and interlaboratory study using dairy products. Journal of AOAC International, v.81, n.3, p.620-632, 1998. 